\title{
CIENTÍFICOS EN NÓMINA: MECENAZGO CIENTÍFICO EN EL OCCIDENTE ISLÁMICO
}

\author{
SCIENTISTS ON PAYROLL: SCIENTIFIC PATRONAGE IN \\ THE WESTERN ISLAMIC WORLD
}

\begin{abstract}
La ciencia fue cultivada, en el occidente islámico, de manera amplia y eficaz, pero ¿quién la financió y por qué? El artículo explora este vastísimo campo a partir de las fuentes árabes que aportan datos (crónicas históricas y diccionarios biográficos) para trazar un panorama del mecenazgo científico. De este modo, además, se contribuye a situar a la ciencia en su contexto social.
\end{abstract}

Palabras clave: Ciencia; mecenazgo; al-Andalus; omeyas.

\author{
MÒNICA RIUS PINIÉS \\ Universitat de Barcelona
}

In the Western Islamic world science was widespread and effectively practiced, but who funded it and why? By exploring those Arabic sources (chronicles and biographic dictionaries) which might shed light on these questions, this paper will try to map the patronage of the sciences and, ultimately, to place the practice of science in its social context.

Key words: Science; Patronage; al-Andalus; Umayyads.

\section{Introducción ${ }^{1}$}

La mayoría de las actividades intelectuales necesitan de un patronazgo para ser ejercidas profesionalmente. Por un lado, se encuentra la voluntad de investigar o crear y hacer de ello, además, un modus vivendi. Por otro, se hallan los intereses - materiales o puramente espirituales - que inducen al mecenas a pagar para que esa actividad sea ejercida. Evidentemente, un sujeto puede patrocinarse a sí mismo y, aunque esta opción normalmente trasluce una voluntad de diletantismo, a veces esconde una elección por la libertad de pensamiento.

Si nos centramos en el caso de la ciencia en su contexto arabo-islámico medieval, debemos prestar atención, en primer lugar, al concepto de ciencia, ya que de otro modo el objeto de estudio se convierte en

${ }^{1}$ Este artículo ha sido escrito dentro del proyecto de investigación "Ciencia y Sociedad en el Mediterráneo Occidental en la Baja Edad Media” del MEC (HUM2004-02511), con ayuda de los fondos FEDER. 
materia confusa. En este artículo, la palabra «ciencia» va a ser utilizada en el sentido de 'ulūm al-awā'il, es decir, en su acepción de «ciencias de los antiguos», destacando la astronomía y la medicina por encima de las otras disciplinas. Quedan fuera los temas relacionados con las ciencias islámicas propiamente dichas si no es en relación con algunos de los temas ya mencionados. Asimismo, se dará una visión diacrónica del mecenazgo en la corte andalusí de época omeya y taifa, centrando el análisis sobre los sectores mencionados - astrólogos y médicos-y su relación con el poder. El objeto de este estudio es pues, responder a la pregunta ¿puede hablarse de científicos profesionales en al-Andalus?

Por otra parte, el mismo concepto de mecenazgo - y de mecenazgo científico - puede interpretarse de muy distintas formas. Aquí va a entenderse como «protección dispensada por una persona a un escritor o artista» ${ }^{2}$ - substitúyase «escritor o artista» por «científico»- y no tanto en el sentido clásico de wala ${ }^{\prime}$ en la doctrina sunní ${ }^{3}$, ya que no se corresponde totalmente con las relaciones establecidas por los científicos estudiados o, al menos, no las explican suficientemente. Las razones de esta particularidad podrían ser tres: el marco geográfico (al-Andalus), el cronológico (siglos IX a XI) y, muy especialmente, las disciplinas que cultivaron los intelectuales objeto de análisis.

Debe notarse que la importancia del patronazgo científico y/o del patronazgo islámico ha sido ya puesta de relieve en numerosos estudios recientes ${ }^{4}$. En el contexto andalusí, si bien las fuentes básicas han sido ya bastante explotadas ${ }^{5}$ y los investigadores contemporá-

2 Es decir, la segunda acepción de la entrada "mecenazgo" del Diccionario de la lengua española, RAE, accesible on-line en http://buscon.rae.es/draeI/ (12-08-08).

3 Crone, P., Roman, Provincial and Islamic Law: The Origins of the Islamic Patronate, Cambridge, 1987; y Fierro, M., "Mawālī and Muwalladūn in al-Andalus (Second/Eighth-Fourth/Tenth Centuries)", en M. Bernards y J. Navas (eds.), Patronate and Patronage in Early and Classical Islam, Leiden, 2005, 195-245.

${ }^{4}$ Tómese como ejemplo la conferencia "The Ancient Sciences at Ayyubid Courts, their Practitioners, Patrons, and Conflicts", que S. Brentjes presentó en el congreso internacional Court Cultures in the Muslim World: Politics and Patronage: 7th-19th Centuries, celebrado en la Schloss Friedenstein de Ghota, del 2 al 5 de julio del 2007; Barker, P. y Goldstein, B., "Patronage and the Production of De Revolutionibus", Journal for the History of Astronomy, 34 (2003), 345-368; Ruggles, D.F. (ed.), Women, Patronage and Self-Representation in Islamic Societies, New York, 2000.

5 Me refiero a las "obras básicas" para el estudio de los científicos andalusíes, como los diccionarios de Ibn Ŷulŷul y de Sā'id de Toledo; a otros diccionarios con información dispersa, como el de Ibn al-Faraḍī; además de obras de carácter histórico general, como el Muqtabis de Ibn Ḥayyān.

Al-Qanțara (AQ) XXIX 2, julio-diciembre 2008, pp. 383-401 ISSN 0211-3589 
neos han enriquecido el panorama con aportaciones indispensables ${ }^{6}$, el análisis desde el punto de vista del mecenazgo merece todavía un examen más pormenorizado ${ }^{7}$.

\section{Emirato}

Parece lógico relacionar cierta estructura política con el establecimiento de un sistema de fomento de determinadas actividades científicas. En la primera época de su presencia en la península, los conquistadores contaban, en sus ejércitos, con sanadores y astrólogos, pero tal presencia no puede entenderse como mecenazgo científico propiamente dicho. Es verdad que algunos orientales de entre los primeros conquistadores de al-Andalus han sido relacionados con las ciencias entendidas de un modo más o menos laxo. Los nombres más mencionados son los de Hanaš al-Șan'ānī o Mūsà b. Nuṣayr ${ }^{8}$, pero en este caso se refiere a habilidades de carácter aplicado (nociones de astrometeorología relacionadas con el sistema de anwā', mīqāt, etc.), más que a estudios científicos patrocinados por alguien.

Este mismo parecer expresa Șā‘id al-Andalusī, ya que une estabilidad social y mecenazgo científico al afirmar que en al-Andalus no había erudición antes de la llegada de los árabes y que, incluso después de la conquista, sus habitantes no sintieron demasiada inclinación por el estudio de las ciencias hasta la instauración del emirato omeya ${ }^{9}$.

${ }^{6}$ En este caso puede ponerse el ejemplo de dos obras fundamentales: Samsó, J., Las ciencias de los antiguos en al-Andalus, Madrid, 1992; y Balty-Guesdon, M.G., Médecins et hommes de science en Espagne musulmane (II $\left./ V I I I^{e}-V^{e} / X I^{e} s.\right)$, tesis doctoral inédita, Université Sorbonne Nouvelle, 1992. Por otra parte, deben tenerse en cuenta, a partir de ahora, los datos que la Biblioteca de al-Andalus. ECA pone a disposición de los investigadores y que pueden ayudar a llevar a cabo nuevas visiones más transversales.

7 Uno de los primeros intentos en este sentido es el de Samsó, J., "A Social Approximation to the History of the Exact Sciences in al-Andalus", en J. Batllo, P. Bernat y R. Puig (eds.), Actes de la VII Trobada d'Història de la Ciència i de la Tècnica, Barcelona, 2003, 519-530 [reimp. en Samsó, J., Astronomy and Astrology in al-Andalus and the Maghrib, Aldershot, 2007].

${ }^{8}$ Marín, M., "Ilm al-nuğùm e 'ilm al-hidțān en al-Andalus", Actas del XII Congreso de la UEAI (Málaga, 1984), Madrid, 1986, 509-535; y Samsó, J., "Astrology, Preislamic Spain and the Conquest of al-Andalus", Revista del Instituto Egipcio de Estudios Islámicos, 23 (1985-1986), 39-54 [reimp. en idem, Islamic Astronomy and Medieval Spain, Aldershot, 1994].

9 Șā‘id al-Andalusī, Kitāb țabaqāt al-umam, L. Cheikho (ed.), Beirut, 1912, 62.

Al-Qanțara (AQ) XXIX 2, julio-diciembre 2008, pp. 383-401 ISSN 0211-3589 
Sea como fuere, el primer astrólogo del que se tiene constancia es al-Ḍabbī (fl. c. 800) ${ }^{10}$. Cuando Hišām (g. 788-796) accedió al emirato no había ningún sistema de predicciones establecido en la corte, de modo que tuvo que mandar un emisario a Algeciras, donde residía al-Dabbī, para pedirle que le pronosticara cómo sería su mandato. ¿Dónde había estudiado y para quién trabajaba al-Dabbī? Calificarle de cortesano es algo desmesurado, pues si bien se relacionó con cuatro emires, su trayectoria no puede inscribirse tanto en el medio cortesano (no tenemos noticia de que estuviera en contacto con sus pares), sino más bien en el misterio de la magia o la brujería. En cualquier caso, tampoco desempeñó funciones administrativas derivadas de su posición de privilegio, por lo que el patrocinio, en este caso, fue bastante limitado.

Es en el Muqtabis II/1 ${ }^{11}$ donde se nos da una información muy precisa sobre la relación laboral que estableció, en especial, 'Abd al-Raḥmān II (g. 821-852) con sus astrólogos ${ }^{12}$. En realidad, según su relato, hasta el emirato de Muhammad (g. 852-886) no se observa una actividad científica digna de tal nombre, precisamente gracias a la labor de impulsor científico que habría llevado a cabo el emir anterior, 'Abd al-Raḥmān II.

Pero para tener una idea del mecenazgo científico debemos responder a la pregunta de cuáles eran las fuentes de ingresos de las que gozaban los científicos. En el caso de algunos astrónomos, podían ejercer como aficionados, ya que su salario provenía de actividades distintas a la ciencia. Es el caso de 'Abbās b. Nāsiḥ, que ocupó el cargo de cadí de Algeciras por lo que, en cualquier caso, formaba parte de los cuadros de la administración. Otros astrólogos - Ibn Firnās ${ }^{13} \mathrm{e}$

10 Samsó, J., "Sobre el astrólogo 'Abd al-Wāhid b. Isḥāq al-Dabbī (fl. c. 788-c. 852)", Anaquel de Estudios Árabes, 12 (2001), 657-669; Rius, M., Enciclopedia de al-Andalus. DAOA, Granada, 2002, 1, 146-147.

${ }^{11}$ Ibn Hayyān, Muqtabis, M.'A. Makkī (ed.), Riyad, 2003; Crónica de los emires Alhakam I y 'Abdarrahmān II entre los años 796 y 847 [Almuqtabis II-1], M.'A. Makkī y F. Corriente (trad. notas e índices), Zaragoza, 2001. Véase el artículo de Forcada, M., "Astronomy, Astrology and the Sciences of the Ancients in Early al-Andalus $\left(2^{\text {nd }} / 8^{\text {th }}-3^{\text {rd }} / 9^{\text {th }}\right.$ Centuries $)$ ", Zeitschrift für Geschichte der Arabisch-Islamischen Wissenschaften, 16 (2004/2005), 1-74.

12 Rius, M., "La relación de los emires con los astrólogos: entre la adicción y el rechazo", en C. de la Puente (ed.), EOBA XIII: Identidades marginales, Madrid, 2001, 517-549.

13 Terés, E., "Abbās ibn Firnās", Al-Andalus, 25 (1960), 239-249 [traducción al inglés en M. Fierro y J. Samsó (eds.), The Formation of al-Andalus, Part 2, Aldershot, 
Ibn al-Šamir ${ }^{14}$ - tenían expresamente asignada una doble paga (una como poetas, la otra como astrólogos), aunque todavía no está claro el motivo por el que esta situación privilegiada estaba restringida a un par de personajes cuando la doble condición de poeta-astrólogo era mucho más amplia ${ }^{15}$. Precisamente, este punto pone en evidencia que la relación económica en el círculo íntimo del emir introducía unos elementos de arbitrariedad que hacen difícil una taxonomía rigurosa. Por este motivo también, en muchas ocasiones los ingresos no eran estables, sino que respondían a meras compensaciones por actuaciones concretas. De este modo, por ejemplo, Marwān b. Gazwān ${ }^{16}$ recibió un premio de mil dinares por acertar una predicción (que si hubiera resultado errónea, le hubiese costado recibir mil azotes). Por otra parte, «al-Gazāl hizo una predicción del precio del trigo por encargo de Nașr, lo que implica que habría actuado como astrólogo al servicio de los intereses de palacio, aunque, en este caso, su actuación profesional no se relacione directamente con el emir sino con el hââyib» ${ }^{17}$. Precisamente, al-Gazāl fue acusado de no rendir cuentas al erario público de manera honesta tras ser encargado él mismo de recoger los impuestos derivados de la recolección del trigo ${ }^{18}$. Otro caso de ciencia al servicio del emir y de la sociedad es el intento de predicción de Ibn 'Azrā' del final de un período de sequía ${ }^{19}$.

En cualquier caso, los científicos, al menos en un momento especialmente favorable como es el caso de los astrónomos de 'Abd al-Raḥmān II, podían reclamar que se les pagara por la prestación de sus servicios, aunque el modo más efectivo de conseguir grandes su-

1998, 10]; y Terés, E., "Sobre el 'vuelo’ de 'Abbas ibn Firnas”, Al-Andalus, 29 (1964), 365-369.

${ }^{14}$ Terés, E., "Ibn al-Šamir, poeta-astrólogo en la corte de 'Abd al-Rahmān II", Al-Andalus, 24 (1959), 449-463; Rius, M., "Ibn al-Šamir”, Biblioteca de ai-Andalus. $E C A$, 5, Almería, 2007, 231-233.

${ }_{15}$ Al menos, no hay más referencias en las crónicas que incluyan otros nombres.

16 Rius, M., "Ibn Gazwān", Biblioteca de al-Andalus. ECA, 3, Almería, 2004, 215-216.

17 Samsó, J., "Cuatro horóscopos sobre muertes violentas en al-Andalus y el Magrib", en M. Fierro (ed.), EOBA XIV: De muerte violenta. Política, religión y violencia en al-Andalus, 2004, 479-519, esp. 487; idem, "Algunas precisiones en torno al horóscopo de Yahyà al-Gazāl sobre la muerte del eunuco Nașr (marzo del 851)", Miscel·lània en Homenatge al P. Agustí Altisent, Tarragona, 1991, 267-269.

18 Rius, M., "al-Gazāl", Enciclopedia de al-Andalus. DAOA, 1, Granada, 2002, 226-229.

19 Samsó, "Cuatro horóscopos", 488.

Al-Qanțara (AQ) XXIX 2, julio-diciembre 2008, pp. 383-401 ISSN 0211-3589 
mas no era la ciencia, sino los versos elogiosos en honor del emir de turno ${ }^{20}$.

Si pasamos a examinar el campo de la medicina, Șā'id al-Andalusī (1029-1070) ${ }^{21}$ afirma que el oriental al-Harrānī, médico personal de 'Abd al-Raḥmān II, logró una gran reputación, algo que no le evitó verse inmerso en intrigas palaciegas. Un poco más tarde, en tiempos del emir Muḥammad, Aḥmad b. Iyās 22 - de clase alta y acomodada - practicó la medicina. Siempre según la opinión de Șāiid, fue el primer andalusí - musulmán - en especializarse en este campo, puesto que antes la gente era tratada por cristianos. Punto y aparte merece Ibn Habīb (m. 853), autor prolífico que dedicó algún estudio monográfico a la medicina y a la astronomía ${ }^{23}$ y que fue maestro de Yahyà b. Yahyà al-Azdī (m. 903), calificado a su vez como especialista en ambas materias. Dicha apreciación resultaría difícilmente aplicable en términos modernos, por lo que simplemente debe llamarse la atención sobre a qué se refieren las fuentes medievales cuando califican a un sabio de «experto en astronomía y medicina».

\section{Califato}

Como se ha visto, según el cadí Șā‘id de Toledo, no entraron científicos en las primeras remesas de conquistadores. El mismo autor pasa prácticamente por alto todo el emirato. Así pues, los primeros nombres propios que aparecen en su libro son Abū 'Ubayda al-Layțī (m. 908), Ibn al-Samīna (m. 967) y Muhammad al-Ḥakīm (m. 943) ${ }^{24}$.

${ }^{20}$ Es el caso de al-Gazāl y de Ibn Firnās, por ejemplo.

21 Martínez-Gros, G., "Șā‘id al-Andalusî”, $E I^{2}, 8,889$.

${ }^{22}$ Cheikho anota en su edición de las Tabaqãt (78) que el laqab no aparece claro en el manuscrito. Si se lee "Ibn Ilyās", y dado que se especifica que era de buena familia, puede conjeturarse que Aḥmad formara parte de los Banū Ilyās, familia de origen beréber documentada desde el inicio de la presencia islámica en la península y con un nutrido grupo de integrantes que trabajaron como funcionarios para diversos emires y califas. Ver Felipe, $\mathrm{H}$. de, Identidad y onomástica de los beréberes de al-Andalus, Madrid, 1997, 137-145.

23 'Abd al-Malik b. Habīb, Kitāb al-Ta'rỉj [La historia], J. Aguadé (ed.), Madrid, 1991; idem, Mujtașar fi l-țibb [Compendio de medicina], C. Álvarez de Morales y F. Girón Irueste (eds. y trads.), Madrid, 1992; Kunitzsch, P., "Abd al-Malik Ibn Habīb's Book on the Stars", Zeitschrift für Geschichte der Arabisch-Islamischen Wissenschaften, 9 (1994), 161-194 y 11 (1997), 179-188.

${ }^{24}$ Práctica común en muchos de estos científicos, el viaje de estudios - y peregrinación- a Oriente ponía a su disposición no solamente a maestros y libros de alto nivel,

Al-Qanțara (AQ) XXIX 2, julio-diciembre 2008, pp. 383-401 ISSN 0211-3589 
Para Șā‘id, la relación entre mecenazgo y cultivo de la ciencia es absoluta. Precisamente, gracias a la labor de mecenas de al-Hakam II (g. 961-976), que empezaría ya antes de su mandato, encontramos un momento de esplendor en el que tendrá bajo su auspicio a un grupo de científicos comparable al de la corte abbasí. Al ser el soberano un modelo de conducta (dedicado al estudio), sus coetáneos se empaparían de la misma actitud ${ }^{25}$.

Ibn Ŷulŷul opina que «los sabios sólo aparecen en los Estados cuyos reyes buscan la sabiduría»" ${ }^{26}$. Para él, el paradigma es 'Abd al-Raḥmān III al-Nāșir (g. 912-961), el califa que más potenció las disciplinas científicas. Pero llegados a este punto, debemos analizar el «perfil profesional» de los científicos que descollaron durante su califato para poder comprobar si Ibn Ŷulŷul estaba en lo cierto. Digno de análisis es, en primer lugar, el médico Yaḥyà b. Isḥāq, quien ostentó un número de cargos impresionante, desarrollando una verdadera carrera administrativa, ascendiendo posición a posición. Ibn Ishạq ejerció, entre otros, los cargos de gobernador, de mediador con el rebelde Ibn Ḥafṣūn, de caíd de Badajoz y de visir. 'Abd al-Raḥmān III también confiaba en él como científico, puesto que dejaba a su cargo la salud de sus esposas y concubinas. Yahyà no salía de la nada ya que su padre, Ishāa b. 'Abd Allāh (m. 903-904), había trabajado como médico en tiempos del emir 'Abd Allāh (g. 888-912) llegando a ser muy popular. No es difícil pensar que la conversión al islam de Ibn Ishāa esté relacionada con su voluntad de medrar en la corte ${ }^{27}$. Así como el padre sufrió el velo de la sospecha que ofrece el que un cristiano tuviera a su cargo la salud de musulmanes, e incluso la del emir, el hijo, Yahyyà, jugó un papel político considerable dada su formación en diversas lenguas. A pesar de que Yahyà ejerció más como político que como médico, tuvo buen cuidado de guardar la tradición familiar, pues al menos uno de sus hijos, Aṣbag, también practicó la medicina.

sino también prácticas que podían ser percibidas, a la vuelta, como "sospechosas". Así, Abū "Ubayda era conocido como Șạhib al-qibla por su "afición" a rezar hacia el este. Además, se destaca que ambos profesaban el mu'tazilismo.

${ }^{25}$ Șā'id al-Andalusī, Țabaqāt, 65-66.

26 Vernet, J., "Los médicos andaluces en el 'Libro de las generaciones de los médicos' de Ibn Ŷulŷul", en Estudios sobre historia de la ciencia medieval, Barcelona, 1979, 469-486 [reimp. de Anuario de Estudios Medievales, 5, Barcelona, 1968].

27 El de esta familia es un caso paradigmático, ya que Almanzor se encuentra en su línea de descendientes, por lo que en pocas generaciones se pasa de profesar el cristianismo a la defensa del islam más enfervorizada. 
Si se considera a Yahyà en su vertiente política, la que le dio sustento durante toda su vida, se entenderá de otro modo la tan manida anécdota de la curación de un campesino que había cohabitado con su asno ${ }^{28}$. Si además se le suma su pasado cristiano, se percibe como natural el que pidiera consejo médico a un monje cuando el califa le hizo saber que sufría un terrible dolor de oídos. Sin ser necesario llegar a un veredicto sobre su capacidad como médico en ejercicio, es interesante destacar que se le atribuye la autoría de una obra, Aforismos, así como una gran amistad con el cirujano al-Zahrāwī. Además de las relaciones verticales - la del califa o el emir con sus cortesanos - es importante constatar la existencia de relaciones horizontales, es decir, la trama de un grupo de intelectuales que intercambiaban sus ideas, establecían relaciones de parentesco y que, en definitiva, llegaron a formar algo similar a una casta aristocrática. Más adelante, se verán otro tipo de relaciones, las de maestro-discípulo, que se hallan ejemplificadas, sobre todo, por la escuela de Maslama.

Conviene señalar que Ibn Ishāa no es un caso aislado, sino que otros médicos combinaron su profesión con cargos en la administración. Abū Bakr Sulaymān b. Bāŷ, médico personal del califa, fue obsequiado con el cargo de cadí, en este caso de Sidonia. El mismo empleo lo ostentó un tercer médico al servicio de 'Abd al-Raḥmān III, Muhammad b. Tamlīj.

El ejercicio de la medicina, como el de la astrología, es otra muestra de que los poderosos trataban con bastante mimo a los científicos especializados en ciencias aplicadas. En las aceifas era tan necesario levantar un horóscopo como tener buenos cirujanos. Al moverse en estos círculos cercanos al poder absoluto, podían saltarse algunas de las normas básicas que otros ciudadanos difícilmente habrían podido eludir. Por ejemplo, Ibn Umm al-Banīn, conocido como al-A'raf, era médico y contertulio del califa a pesar de tener un carácter excesivamente altivo ${ }^{29}$. Las fuentes nos informan de que el califa dependía de él a causa de su conocimiento científico ${ }^{30}$. Lo anterior no hace más que corroborar la máxima que afirma que «saber es poder», y de-

28 Vernet, J., "Los médicos andaluces", 456-457.

${ }^{29}$ Incluso a pesar de haber llevado a cabo prácticas homosexuales en público. Sobre la importancia de mantener en el ámbito privado las relaciones homosexuales véase Adang, C., "Love between Men in Țawq al-Hamāma", en Puente (ed.), EOBA XIII: Identidades marginales, 2001, 111-145.

30 Vernet, J., "Los médicos andaluces", 458.

Al-Qanțara (AQ) XXIX 2, julio-diciembre 2008, pp. 383-401 ISSN 0211-3589 
muestra, además, que los hilos del poder real no siempre están en la cúspide de la pirámide.

El mismo mensaje se repite bastante, con lo que queda patente que algunos poderosos gustaban de rodearse de científicos, a los que por supuesto necesitaban, y que éstos llegaban a enriquecerse gracias a la proximidad con el poder. Eso sí, la proximidad al califa no era necesariamente exclusiva. Ya se ha visto cómo, en época emiral, Nașr utilizaba los servicios de al-Gazāl y de al-Harran̄i. Hay constancia de que durante el califato Abū Ḥafs 'Umar b. Burayq, por ejemplo, sirvió a 'Abd al-Raḥmān III, pero también a Naŷm b. Țarafa, jefe de los halconeros y verdadero mecenas de su arte. El mismo Naŷm introdujo en la corte a Abū 'Abd al-Malik al-Taqafī, quien llegó a ser médico de 'Abd al-Raḥmān III y de al-Hakam II, por lo que la influencia de Naŷm ante los califas parece evidente. Por otra parte, sus protegidos estaban sólidamente formados. Abū 'Abd al-Malik al-Taqafī, además de medicina, también tenía conocimientos de geometría y aritmética y logró ser nombrado jefe del arsenal.

Aḥmad b. Hakam b. Hafșun, por su parte, se relacionó con el hââyib Ŷa'far al-Ṣaqlabī y se encargaba, asimismo, de la salud de la gente de alta alcurnia. Más tarde entró directamente al servicio del califa al-Hakam, pero al morir el ḩâyib Ŷa'far, fue relegado de la corte.

El prestigio fue algo común a muchos de estos personajes. Es el caso del médico Aṣbag b. Yahyà que, llegado a la vejez, fue un anciano muy poderoso y respetado en las asambleas. Muhammad $b$. Tamlīj, además de reunir los cargos de juez y cadí de Sidonia, como ya se ha visto, fue encargado de la distribución de la sadaqa. Había sido ya médico de 'Abd al-Raḥmān III y fue contertulio de al-Hakam, quien le encargó la ampliación de la mezquita aljama, motivo por el cual su nombre fue grabado en la parte superior del mi hrāab del edificio. También fue grabado su nombre en los dinares, por ser inspector de la casa de la moneda. El perfil de estos personajes, una vez más, es el de cortesanos formados y no tanto el de científicos a sueldo.

La imagen que ofrece de la profesión médica Ibn Ŷulŷul puede tener múltiples lecturas, desde la crítica a la política cultural de Almanzor, hasta un anecdotario ilustrador de buenas costumbres ${ }^{31}$. Las ausencias en este libro son tan llamativas como el retrato, casi

31 Álvarez-Millán, C., "Medical Anecdotes in Ibn Juljul's Biographical Dictionary", Suhayl, 4 (2004), 141-158.

Al-Qanțara (AQ) XXIX 2, julio-diciembre 2008, pp. 383-401 ISSN 0211-3589 
histriónico, de los médicos biografiados. En cualquier caso, prácticamente todos los médicos de la novena generación que aparecen están al servicio de los califas o altos mandatarios de la corte andalusí, por lo que suponen una visión sesgada de la realidad social de los médicos en al-Andalus. En efecto, el mismo Ibn Ŷulŷul trabajó al servicio de al-Hakam II y Hišām II. En su caso, al menos, no hay que dudar de su competencia teórica, ya que además de su obra sobre los colegas de profesión, también redactó tratados propiamente médicos ${ }^{32}$.

Por otra parte, Sāaid tampoco ensalza en demasía la categoría científica de estos profesionales. Según el toledano, no había médicos dignos de mención en al-Andalus, excepto algunas personalidades contadas. Es más, les reprocha que, en general, no tengan una actitud intelectual, y que su afán sea solamente el de enriquecerse cerca de los poderosos. Cabría, pues, hacer una fina distinción entre la calificación del dottore a la italiana ${ }^{33}$ y la de los verdaderos profesionales de la medicina. En las biografías de muchos de los científicos se les atribuye maestría en los más diversos campos: matemáticas, medicina, astronomía, tradición, jurisprudencia, Corán, lengua, poesía..., con lo que debemos deducir que, en muchas ocasiones, no deben considerarse científicos profesionales, sino cortesanos que habían estudiado, entre otras materias, la medicina. Podría ser el caso de Ibn al-Bagūniš (m. 1052). Este erudito estudió en Córdoba con los mejores maestros (matemáticas con Maslama de Madrid, medicina con Ibn 'Abdūn al-Ŷabalī ${ }^{34}$, con Muhammad b. al-Šanā'a y con el mismo Ibn Ŷulŷul), pero de vuelta a su ciudad, Toledo, trabajó en la corte al servicio de al-Zāfir (g. 1018, 1032-1043) y de al-Ma'mūn (g. 10431075). Sāa'id transmite que a pesar de ser un gran erudito, no dominaba el ejercicio de la medicina, lo que no le impidió ser maestro de un buen médico, Abū 1-Ḥasan 'Abd al-Raḥmān b. Jalaf b. 'Asākir al-Dārimī. Como profesional, la talla de Ibn al-Bagūniš parece poco comparable a la de su colega Ibn Wāfid (m. 1075) ${ }^{35}$, quien realmente

32 Samsó, "Las ciencias de los antiguos", 114-116 y 273.

${ }^{33}$ Que llegó a convertirse en un personaje fijo en los canovaccios de la Commedia dell'Arte.

${ }^{34}$ Djebbar, A., "Ibn 'Abdūn's Epistle on Surface Measuring: A Witness to the pre-Algebraical Tradition”, Suhayl, 5 (2005), 7-68 (Arabic section) y Suhayl, 6 (2006), 81-86 (Arabic section).

35 Álvarez de Morales, C. y Carabaza, J.M., "Ibn Wāfid", Biblioteca de al-Andalus. ECA, 5, Almería, 2007, 565-569.

Al-Qanțara (AQ) XXIX 2, julio-diciembre 2008, pp. 383-401 ISSN 0211-3589 
estaba habituado a tratar enfermos y que había elaborado una buena práctica consistente en intentar sanar, en primera instancia, a través de la dieta para evitar una ingesta de fármacos si no era necesaria.

En alguna ocasión, esta relación con la corte era tan sólida que pasó a formar parte del laqab del propio científico. Así, 'Arīb b. Sa'īd fue conocido como al-Kätib (m. c. 980). 'Arīb, intelectual formado en multitud de disciplinas - práctica habitual como se ha visto - era ducho en medicina, agronomía, historia y poesía. Trabajó al servicio de 'Abd al-Raḥmān III, al-Ḥakam II y Almanzor, llegando a ser nombrado gobernador de la cora de Osuna. En este caso, sin embargo, la ostentación de un cargo no fue impedimento para escribir obras científicas de valor ${ }^{36}$.

En cuanto al apego que pudieran tener por los bienes materiales, en la biografía de Abū l-Walīd Muhammad b. Husayn (m. 1029), se especifica que fue apreciado tanto por las altas esferas (fue médico de 'Abd al-Rahmmān III y de al-Hakam II) como por el vulgo ${ }^{37}$. Algunos, más radicales, como Muhammad b. Fath b. Tamlūn (cliente de 'Imrān b. Abī 'Umar [m. 932] médico de 'Abd al-Raḥmān III), simplemente se negaron a trabajar en la corte, o al menos, al servicio del califa, ya que Ibn Ŷulŷul transmite la anécdota de que curó al hijo del visir 'Abd Allāh b. Badr y que por ello recibió cincuenta dinares y un traje de corte.

Sa'īd b. 'Abd al-Raḥmān b. 'Abd Rabbihi (m. 953 ó 966), sobrino del poeta Ibn 'Abd Rabbihi (860-940) y cliente del califa Hišām II (g. 976-1000, 1010-1013), fue a la vez excelente médico y poeta, interesándose también por la astronomía. Pero, según Șā‘id, tomó una sabia decisión al vivir de manera honesta, esto es, apartado de la corte y sus tentaciones. Sin embargo, debió tener vocación pedagógica puesto que entre sus obras cabe mencionar una Urŷuza fi l-țibb ${ }^{38}$.

Pertenecer a una buena familia también era una ventaja. Abū 1-Walīd Muhammad b. al-Ḥusayn al-Kattānī fue médico de 'Abd al-

${ }^{36}$ Forcada, M., "The Kitāb al-Anwā' of 'Arīb b. Sa'īd and the Calendar of Cordova", en M. Folkerts y R. Lorch (eds.), Sic Itur ad Astra: Studien zur Geschichte der Mathematik und Naturwissenschaften Festschrift für den Arabisten Paul Kunitzsch zum 70, Wiesbaden, 2000, 234-251.

37 Eso no le impidió tener un rutilante negocio de venta de esclavas, a las que formaba en una escuela selecta.

38 Kuhne, R., "La Urŷūza fi l-țibb de Sa'īd ibn 'Abd Rabbihi”, Al-Qanțara, 1 (1980), 279-388.

Al-Qanțara (AQ) XXIX 2, julio-diciembre 2008, pp. 383-401 ISSN 0211-3589 
Raḥmān III y de al-Hakam II, mientras que un descendiente suyo, Abū 'Abd Allāh Muhammad b. al-Hasan, conocido como Ibn al-Kattānī, fue médico de Almanzor y de su hijo al-Muẓaffar, hasta que al estallar la fitna emigró a Zaragoza. La integración en el sistema puede percibirse por su larguísima lista de maestros (Ibn 'Abdūn al-Ŷabalī, al-Hammār al-Saraqusțī, 'Umar b. Yūnus al-Harrānī, Ibn Hafsūn, Ibn Marīn al-Baŷŷānī, Rabī‘ b. Zayd, Ibn al-Dahabī...), por tener como discípulo a Ibn Hazm, así como por haberse dedicado a la formación de las esclavas cantoras.

Como era ya tradición, los contactos de los científicos andalusíes con el Oriente islámico fueron fluidos ${ }^{39}$. Abū Hafṣ 'Umar b. Burayq, por ejemplo, antes de entrar al servicio de 'Abd al-Raḥmān III y de Naŷm b. Tarafa, estudió una temporada en Qayrawān bajo la tutela de Abū Ŷa ‘ar b. al-Ŷazzār. Algunos andalusíes, incluso, llegaron a gozar de prestigio también en el Mašriq. Tal es el caso de Muḥammad b. 'Abdūn al-Ŷabalī (m. 971) que vivió una temporada en Oriente, llegando a dirigir el maristān de al-Fusțāt. A su regreso a al-Andalus, sirvió como médico de al-Hakam II y Hišām II. Además, antes de ejercer la medicina había sido profesor de matemáticas ${ }^{40}$.

Dos hermanos, tal vez descendientes de al-Ḥarrānī, 'Umar y Ahmad, también siguieron el mismo camino y tras un viaje de estudios de alto nivel a su tierra de origen ${ }^{41}$, fueron médicos personales de al-Hakam II, trabajando en la misma Medina Azahara y acompañando al califa en sus algazúas. Ahmad, en particular, estuvo encargado de la salud de las mujeres del califa así como de la farmacia de palacio (desde donde practicaba «justicia social», es decir, cobraba a los ricos y no a los pobres). Pero tal y como se ha visto en otros casos, la medicina fue compartida con otros muchos quehaceres. Hišām II, por ejemplo, nombró a Ahmad jefe de policía e inspector de los mercados.

El fin del califato, sin embargo, anuncia un cambio de perspectiva. Si veíamos a al-Hakam II como un verdadero mecenas bibliófilo, con Almanzor la relación sería absolutamente la contraria: los libros se reúnen para quemarlos. La explicación es sencilla: un mal líder debe

\footnotetext{
${ }^{39}$ Se han mencionado ya las estancias de Abū 'Ubayda al-Layțī, Ibn al-Samīna y Muhammad al-Hakīm.

${ }^{40}$ La única obra suya que se conoce, el Kitāb mujtașar ŷāmi 'li-wuŷūh al-misāha, no versa sobre medicina, sino sobre agrimensura.

${ }^{41}$ Estudiaron con Taābit b. Sinān b. Taābit b. Qurra e Ibn Wașîf.
}

Al-Qanțara (AQ) XXIX 2, julio-diciembre 2008, pp. 383-401 ISSN 0211-3589 
legitimarse ante sus súbditos y así puede tomar decisiones «populistas» como, por ejemplo, desacreditar públicamente la ciencia, si piensa que de ese modo el pueblo será más dócil ${ }^{42}$. Este aspecto es sumamente importante, puesto que precisamente por el ideal de príncipe-sabio ${ }^{43}$, quien dirige la comunidad también puede y debe marcar qué disciplinas deben estudiarse y cuáles no. Se fomenta el mecenazgo de unas materias, se prohíbe el análisis de otras. Incluso podríamos calificar de exilio el éxodo de algunos científicos. Al-Uqlīdisī ${ }^{44}$, por ejemplo, emigró de al-Andalus hacia Oriente en época de Almanzor y lo mismo pasó con al-Ḥammār al-Saraqusțī ${ }^{45}$.

Otro aspecto característico, aunque no exclusivo, de Almanzor es la hipocresía, es decir, aborrece la astrología y se comporta como un antimecenas científico cuando no le gustan los «resultados», si bien no siente reparos en utilizarla en el momento en que le parece conveniente ${ }^{46}$. Me refiero, por ejemplo, a que mandó arrestar a todo aquel que se atrevía a pronosticar que su régimen estaba a punto de expirar, pero en cambio encargó el horóscopo natalicio de su hijo al-Muzaffar (g. 1002-1008) ${ }^{47}$. Atento al comportamiento del soberano, Aḥmad b. Fāris (m. 981) ${ }^{48}$, que ya había trabajado con anterioridad para al-Hakam II, tuvo la precaución de asegurarse de que el horóscopo de al-Muzaffar fuera totalmente favorable para evitarse cualquier tipo de problema.

De todos modos, e independientemente de quién ostente el poder, en un momento en que la ciencia en al-Andalus está ya consolidada, muchos de los científicos se constituyen en grupos. Tenemos constancia de las cadenas maestro-discípulo en diversos casos: Ibn al-Jayyāt

42 Sāaid al-Andalusī, Țabaqāt, 66-67.

43 Stroumsa, S., "Philosopher-King or Philosopher-Courtier? Theory and Reality in the Falāsifa's Place in Islamic Society", en Puente (ed.), EOBA XIII: Identidades marginales, 2001, 433-459.

${ }_{44}$ Más teniendo en cuenta que era hijo de un funcionario de la corte de al-Hakam II, versado en lengua y poesía.

${ }^{45}$ En este caso, debido a la heterodoxia con que eran percibidos algunos estudios filosóficos. Véase Fierro, M., "al-Hammār", Enciclopedia de al-Andalus. DAOA, 1, Granada, 2002, 238-239; y, de modo más genérico, idem, La heterodoxia en al-Andalus durante el periodo omeya, Madrid, 1987.

46 J. Vernet ya demostró que Almanzor tenía sumo cuidado en emprender sus campañas en momentos astrológicamente favorables. Vernet, J., "Astrología y política en la Córdoba del siglo X", Revista del Instituto Egipcio de Estudios Islámicos, 15 (1970), 91-100.

47 Samsó, "Cuatro horóscopos", 488-489.

48 Forcada, M., "Astrology and Folk Astronomy: The Mukhtașar min al-Anwā' of Aḥmad b. Fāris", Suhayl, 1 (2000), 107-205. 
(m. 1055-1056) ${ }^{49}$ era discípulo de Maslama al-Maŷrītī, lo que demuestra una conexión Córdoba-Toledo; Abū 'Uțmān Sa'īd b. Muhammad al-Bagūniš al-Ṭulayțulī, como se ha mencionado, fue también discípulo de Maslama quien, a su vez, lo fue de Abū Bakr b. Abī 'Īsà ${ }^{50}$, quien ya enseñaba aritmética, geometría y astrología en época de al-Hakam II. En efecto, Maslama (m. c. 1005) ${ }^{51}$ es el líder de la escuela conocida por su nombre. Baste fijar la atención aquí del interés que tiene poder hablar de una escuela científica que, además, ya fuera considerada como tal en su tiempo. Así nos lo describe Sāàid, quien adjudica a Maslama un listado de discípulos: Ibn al-Samh (m. 1035) ${ }^{52}$, Ibn al-Ṣaffār (m. 1035) ${ }^{53}$, al-Zahrāwī, al-Kirmānī (m. 1066) e Ibn Jaldūn (m. 1057). Asimismo, discípulo de Ibn al-Samh fue Abū Marwān Sulaymān b. Muḥammad b. 'İsà al-Nāšñ, mientras que de Ibn al-Saffār lo fueron Ibn Bargūt (m. 1052-3), al-Wāsițī, Ibn Šahr (m. 1043), al-Qurašī al-Afțas al-Marwānī (m. 1045) e Ibn al-'Atṭār. Conviene señalar que este último era un liberto de Muhammad b. Abī Hurayra, jādim del rey de Toledo al-Zāfir. A su vez, algunos de estos alumnos destacados se dedicaron a la docencia en Córdoba, como al-Wāsiṭi o Ibn al-'Atțār. Ibn Šahr, en cambio, también era especialista en fiqh y fue nombrado cadí de Almería.

Muchos de estos científicos vivieron a caballo entre el califato y la fitna, acontecimiento político que marcó la vida intelectual de al-Andalus. A partir de ese momento, los mecenas no se encuentran sólo - o principalmente - en la capital, sino que los centros se dispersan por la geografía de la península.

49 Samsó, J. y Lirola, J., "Ibn al-Jayyāṭ”", Biblioteca de al-Andalus. ECA, 3, Almería, 2004, 723-725.

50 Sobre el epónimo Abū 'Īsà, véase Marín, M., "Una familia de ulemas cordobeses: los Banū Abī 'Īsà”, Al-Qanțara, 6 (1985), 291-300. Șā‘id describe a Abū Bakr como descendiente de un sahāba, pero la coincidencia en el espacio y el tiempo (corte cordobesa en tiempos del califato) con la familia mawlà de origen beréber Abū 'Ĩsà parece sospechosa.

51 Samsó, J., "Maslama ibn Aḥmad al-Maŷrīṭī", Diccionario Biográfico Español, Madrid, en prensa.

52 Comes, M., "Ibn al-Samh", Biblioteca de al-Andalus. ECA, 5, Almería, 2007, 227-230; Rius, M., "Ibn al-Samh", en T. Glick, S.J. Livesey y F. Wallis (eds.), Medieval Science, Technology, and Medicine, New York, 2005, 241-242.

53 Samsó, J., "Ibn al-Șaffār", Biblioteca de al-Andalus. ECA, 5, Almería, 2007, 69-73; Rius, M., "Ibn al-Șaffār", en Glick et al. (eds.), Medieval Science, 240.

Al-Qanțara (AQ) XXIX 2, julio-diciembre 2008, pp. 383-401 ISSN 0211-3589 


\section{Taifas}

Siendo una época de disgregación política no es, sin embargo, un momento en el que la ciencia esté en crisis. Ahora bien, los mecenas se multiplican y, si bien la capacidad económica de un rey de taifa era menor que la de un califa, aquéllos no dejaron de invertir, quizá como modo de publicitar su acción gobernadora. Una situación que empieza de forma negativa, en la que los reyes de Córdoba venden sus libros por unos pocos ingresos, se convierte en otra positiva, ya que los materiales cambian de manos y acaban por llegar a las personas que tienen ansias de aprender hasta que, finalmente, son los reyes de taifas los que se convierten gradualmente en mecenas de las ciencias ${ }^{54}$. Esta es, según Șā‘id, la causa que explica por qué los reyes de taifas sí patrocinan la ciencia, a pesar de que la circunstancia política de lucha contra los reinos cristianos impida que el apoyo sea económica y moralmente mayor de lo que ellos mismos desearían.

Es en esta época, pues, cuando hallamos a las máximas estrellas del universo científico andalusí: Azarquiel o el mismo Mu'taman de Zaragoza, son algunos de los ejemplos más significativos. De este modo, no debe unirse fragmentación política con decadencia científica; al contrario, el proyecto del califato omeya, si bien tuvo grandes fisuras en el campo político, dio sus resultados en el científico. Siglos de importación de materiales, de viajes de estudios a Oriente y de mecenazgo, aunque fuera irregular, acaban dando como fruto una ciencia madura. El proceso de importación no se dará por terminado, naturalmente, y todavía deberán llegar algunas obras que marcarán el devenir del pensamiento andalusí. Es el caso de al-Kirmānī (discípulo de Maslama y maestro de al-Husayn b. Muhammad b. al-Husayn b. Ḥayy al-Tuŷībī), quien viajó a Ḥarrān, donde estudió medicina y, a su vuelta a al-Andalus, trajo consigo las Rasā'il Ijwān al-Safä'.

En el tránsito entre el califato y las taifas, surge uno de los momentos estelares de la astronomía. Ibn al-Jayyāț, discípulo de Maslama al-Maŷrītī, empieza trabajando para Sulaymān al-Musta'īn (g. 1010 y 1013-1016), pero más tarde debe peregrinar para trabajar al servicio de diversos príncipes, el último de los cuales es el toledano al-Ma'mūn para el que escribió la Risāla fì l-qirānāt al-nuŷümiyya, obra en la que se determinaba el fin de la permanencia de los musul-

${ }^{54}$ Ṣā‘id al-Andalusī, Țabaqāt, 66-67.

Al-Qanțara (AQ) XXIX 2, julio-diciembre 2008, pp. 383-401 ISSN 0211-3589 
manes en al-Andalus. También de astrología política es su predicción sobre la conquista de Denia por al-Muqtadir b. Hūd, noticia transmitida por otro soberano, 'Abd Allāh b. Buluqqīn, que da cuenta de ello, además del horóscopo de la muerte del astrólogo, en su Tibyān.

Como es habitual, Sāa id hace hincapié en la profunda religiosidad - que se demuestra en el dominio de las ciencias religiosas- de muchos de los científicos de este período ${ }^{55}$. Así pues, en su lista de científicos incorpora a Abū Ayyūb 'Abd al-Gafīr b. Muhammad (discípulo de Ahmad b. Jālid y maestro de Maslama) o a 'Abd Allāh b. 'Ubayd Allāh, conocido como al-Sarī, versado en aritmética y alquimia, pero también en Corán, fiqh y ascetismo. De este segundo personaje llama la atención el que, a pesar de que al-Hakam II quisiera patrocinarle y tenerle en su círculo, prefiriera llevar una vida ascética lejos de la corte. Ibn Bargūt, por su parte, era matemático y astrónomo, pero también alfaquí y experto en Corán al igual que Ibn Šahr, nombrado cadí de Almería durante el emirato de Zuhayr al-'Āmirī. Muhammad b. Ahmmad b. Muhammad b. al-Layt (m. 1058), discípulo de Ibn Bargūt, era cadí en la región de Valencia, pero destacaba en el conocimiento de otras disciplinas como la astronomía y la geometría. Ibn al-Waqašīi, del que su discípulo Șā‘id habla con veneración, ejerció de cadí en Talavera (perteneciente a la taifa de los Dū l-Nūn de Toledo), siendo a su vez competente en otros muchos saberes, entre los que se cuentan la geometría, la lengua, la poesía o el hadịt. Ibn $\mathrm{Mu}^{\mathrm{a}} \mathrm{a} \mathrm{d}$ (m. 1093) destacó en matemáticas y astronomía, pero también en fiqh, por lo que ejerció de cadí en Jaén. En cambio, un gran médico, Abū 1-'Arab Yūsuf b. Muhammad (m. 1039), fue un bebedor empedernido que no podía apenas ejercer, ya que estaba constantemente ebrio.

En Toledo trabajaron Azarquiel (m. 1100) ${ }^{56}$ o Ibn Jalaf al-Istîŷŷ̀ ${ }^{57}$. Las fuentes pueden inducir a una visión algo idílica de la

55 Bien es cierto que hay campos, como el de las matemáticas aplicadas al cálculo sucesorio, que nunca han sido sospechosos de herejía.

${ }^{56}$ Ibn al-Naqqāš al-Zarqālluh, al-Šakkāziyya, R. Puig (ed. y trad.), Barcelona, 1986; Samsó, J., "al-Zarkalī", EI $, 11,461-462$; Comes, M., Ecuatorios Andalusíes. Ibn al-Samh, al-Zarqālluh y Abū l-Salt, Barcelona, 1991, 203.

57 Samsó, J., "Ibn Jalaf al-Istîŷ”", Biblioteca de al-Andalus. ECA, 3, Almería, 2004, 565-568; Samsó, J. y Berrani, H., "World Astrology in Eleventh-Century al-Andalus: The Epistle on Tasyir and the Projection of Rays by al-Istijji”", Journal of Islamic Studies, 10 (1999), 293-312; idem., "The Epistle on Tasyir and the Projection of Rays by Abū Marwān al-Istijī”, Suhayl, 5 (2005), 163-242.

Al-Qanțara (AQ) XXIX 2, julio-diciembre 2008, pp. 383-401 ISSN 0211-3589 
cultura en Toledo en época taifa, ya que lo cierto es que no solamente sus soberanos, sino cierta élite, como el mismo Șā‘id, patrocinaron a un número importante de científicos de diversas disciplinas. De este modo, Ibn Jalaf, posiblemente nombrado para un cargo importante en Cuenca, también bajo la jurisdicción de los Banū Dī 1-Nūn, dedicó su tratado sobre la proyección de los rayos al mismo Șā'id, muy interesado en la astrología. Cabe mencionar que Șā‘id ejercía de cadí en Toledo y que recibía por ello el título de wazìr. No es de extrañar que el gran biógrafo científico, y a su vez mecenas, sea precisamente de este período y de esta ciudad.

Otro Ibn Jalaf, 'Alī b. Jalaf al-Ṣaydalānī ${ }^{58}$, también coincidió en tiempo y lugar: en el equipo de astrónomos de Șā'id en Toledo. El que algunos de ellos sean muy sobresalientes induce a pensar que el caldo de cultivo era especialmente favorecedor. Además, en este contexto, la ciencia y la política podían ir de la mano sin ningún problema. El toledano Abū 'Uțān Sa'īd b. Muḥammad b. al-Bagūnīš, como se ha visto, se formó en Córdoba pero trabajó en su ciudad natal al servicio de al-Ma'mūn, de quien fue visir. Es curioso observar que su formación científica le daba solidez intelectual, pero que no tenía como finalidad directa el convertirse en profesión. De este modo, su formación médica era totalmente libresca, sin que tuviera capacidad de tratar a individuos de carne y hueso. Al final de su vida, decidió retirarse del mundanal ruido y concentrarse en el estudio del Corán.

Abū Ishāq b. Ibrāhīm b. Lubb b. Idrīs al-Tuŷībī, conocido como al-Quwaydis (m. 1062), era de Calatayud pero se trasladó a Toledo, donde estudió astronomía y donde posteriormente ejerció el magisterio de la lengua árabe.

A pesar de todo, la supervivencia en un medio de fragmentación política y de cambio frecuente era difícil. Azarquiel trabajó primero en Toledo y, más tarde, se trasladó a Córdoba. Es natural que sus obras estén dedicadas a al-Ma'mūn de Toledo y, posteriormente, a al-Mu'tamid de Sevilla (g. 1069-1091). No obstante, cabe recordar que Córdoba estuvo en manos sevillanas entre 1070 y 1075, que en los tres años siguientes pasó a estar controlada por la taifa toledana y que, finalmente, volvió a la tutela 'abbadí, eso sí, no por mucho tiempo, puesto que en 1091 la ciudad era conquistada por los almorávides.

58 Puig, R., "Ibn Jalaf al-Șaydalānī”, Biblioteca de al-Andalus. ECA, 3, Almería, 2004, 570-571.

Al-Qanțara (AQ) XXIX 2, julio-diciembre 2008, pp. 383-401 ISSN 0211-3589 
No perder el favor de los gobernantes podía ser considerado un auténtico arte.

El mecenazgo, pues, se convierte en temporal y, de este modo, los científicos tendrán que emigrar a otras taifas en caso de necesidad. Gracias a las notas biográficas de personajes como Abū 1-Qāsim Aḥmad b. al-Ṣaffār queda constancia de que primero trabajó en Córdoba de maestro, pero al inicio de la fitna optó por trasladarse a Denia, capital de Muŷāhid al-'Āmirī, al igual que su hermano Muhammad, constructor de astrolabios. Ibn al-Samh, que murió en Granada en 1035, estuvo al servicio de Habbūs b. Maksān b. Zīrī. También en Granada residió al-Zahrāwī, quien fue imām y jațīb de la aljama de la ciudad. Ibn al-Ŷallāb (perteneciente a la escuela de Maslama y especialista en cosmología) trabajó en Almería, taifa gobernada por al-Mu'tașim, de los Banū Sumādih. Más espectacular es el caso de Ibn al-Hayy (m. 1064 ó 1065), astrónomo cordobés que se trasladó a Egipto y, más tarde, al Yemen donde trabajó al servicio del emir al-Ṣulayhị̄, quien llegó a enviarle como embajador ante el califa de Bagdad, al-Qā'im (g. 1031-1075).

El caso de Mu'taman de Zaragoza, finalmente, es el del mecenazgo científico llevado al máximo, puesto que es el mismo mecenas el que, en su interés, practica la materia que patrocina. Tampoco es extraño que el rey fuera un intelectual, puesto que la labor de mecenazgo de los hudíes en la taifa había sido alimentada durante años, sin olvidar que tal labor había empezado ya incluso antes del derrumbamiento del califato. Se ha mencionado el paso por Zaragoza de Ibn al-Kattānī o de al-Kirmānī. Entre Zaragoza y Valencia circuló el matemático y astrónomo 'Abd Allāh b. Aḥmad al-Saraqusțī (m. 1056); y en Zaragoza también se hallaba su discípulo 'Alī b. Naŷda b. Dāwūd, así como otro matemático, Abū Ŷa'far Ahmad b. Ŷawšan b. 'Abd al-'Azīz b. Ŷawšan. La taifa se convirtió, asimismo, en un núcleo de científicos judíos, muchos de ellos especialistas en medicina. Póngase como ejemplo a la saga de los Ibn Šaprūṭ, a Ibn al-Fawwāl o a Abū 1-Walīd Marwān b. Ŷanāḥ (m. c. 1040).

\section{Conclusiones}

Ciencia y mecenazgo son campos unidos desde antaño. Sin embargo, de entre todas las posibilidades, la ciencia aplicada (matemáti- 
cas, astronomía, medicina) ha sido la más subvencionada. En realidad, no hace falta alcanzar el grado de sociedad política y económicamente estable para contar en las filas de los ejércitos con astrólogos y médicos. Estas exigencias en el resultado práctico condicionaban los campos de estudio, de modo que la investigación en temas más teóricos resultó, en algún momento, poco atractiva a los ojos del poder.

La medicina, sobre todo en su etapa más alejada de la filosofía, no fue considerada, en general, como algo sospechoso por la religión o las costumbres. Sin embargo, otra de las ramas de la ciencia más practicada, la astrología, transitó por veredas entre la ortodoxia y la heterodoxia, hecho que provocó que los astrólogos, y también sus patrocinadores, buscaran soluciones políticamente correctas, intentando justificar la licitud de sus artes o simplemente escondiendo su práctica. En cualquier caso, la relación entre astrología y política potenció en todo momento el mecenazgo de los astrólogos.

De todos modos, el número de científicos que aparecen en las biografías debe ser puesto sobre un tamiz. Haber estudiado matemáticas no convierte a un individuo en matemático. Si nos centramos en las altas esferas, debe considerarse que las ciencias de los antiguos eran estudiadas porque formaban parte del plan de estudios del buen cortesano. Así pues, no es de extrañar que muchos autores, a pesar de ser supuestamente médicos, por ejemplo, ni escribieran obras sobre medicina ni tuvieran capacidad de tratar a enfermos.

De todos modos, y a la espera de que este campo siga siendo labrado, puede establecerse una primera catalogación de los científicos andalusíes en tres grupos: a) los cortesanos que tenían conocimientos de diversas materias, entre ellas las científicas; b) los científicos que, además de trabajar en la investigación, ostentaron cargos administrativos o llevaron a cabo misiones diplomáticas; y c) los científicos profesionales que se dedicaron exclusivamente al estudio de su disciplina.

Recibido: $26 / 02 / 08$

Aceptado: 05/06/08 